\title{
Endoscope-Assisted Microsurgical Removal of an Optic Foramen Meningioma through a Frontolateral Minicraniotomy
}

\author{
Peter Kurucz ${ }^{1}$ Holger Opitz ${ }^{1}$ Michael Buchfelder ${ }^{2}$ Oliver Ganslandt ${ }^{1}$
}

${ }^{1}$ Department of Neurosurgery, Klinikum Stuttgart, Stuttgart,

Address for correspondence Peter Kurucz, MD, Neurochirurgische Germany

2 Department of Neurosurgery, Friedrich-Alexander University, Klinik, Katharinenhospital, Kriegsbergstrasse 60, 70174, Deutschland Erlangen-Nuremberg (FAU), Erlangen, Germany (e-mail: p.kurucz@klinikum-stuttgart.de).

J Neurol Surg B 2018;79(suppl S2):S227-S228.

\begin{abstract}
Keywords

- optic foramen meningioma

- frontolateral keyhole approach

- endoscope-assisted microsurgery

A 72-year-old male patient with visual disturbance of the right eye was diagnosed with a small meningioma of the right optic foramen extending to the carotid cistern. The operation was performed through an individually tailored frontolateral minicraniotomy via a curvilinear skin incision behind the hairline. Endoscope-assisted microsurgical technique was used to resect the lesion. The roof of the optic canal was partly removed to get access to the intraforaminal tumor parts. The lesion could be completely removed and the patient showed a satisfactory visual recovery in the follow-up examinations.

The link to the video can be found at: https://youtu.be/p8EZx7aryeQ.
\end{abstract}

Conflict of Interest

None.

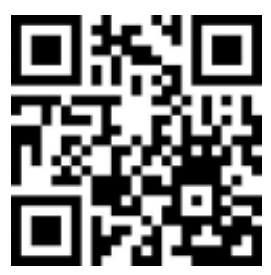

www.thieme.com/skullbasevideos

www.thieme.com/jnlsbvideos

received

September 1, 2017 accepted

December 12, 2017

published online

January 15, 2018
DOI https://doi.org/

10.1055/s-0037-1620246.

ISSN 2193-6331. (c) 2018 Georg Thieme Verlag KG

Stuttgart · New York
License terms

() (i) $\ominus$ (\$) 

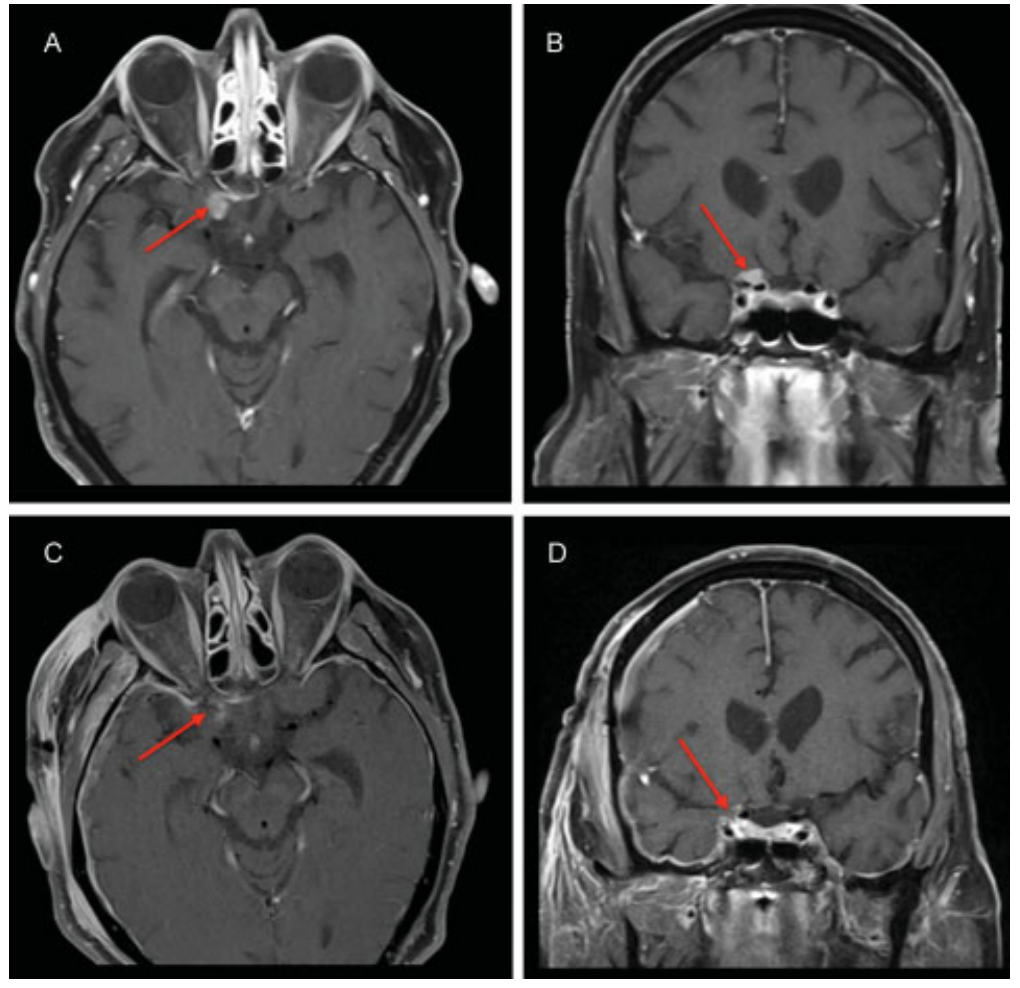

Fig. 1 (A, B) Preoperative contrast agent-enhanced MRI scans of the head revealed a small lesion of the right optic foramen just medially to the anterior clinoid process (red arrows). (C, D) Postoperative contrast agent-enhanced MRI scans of the head show complete tumor removal (red arrows). MRI, magnetic resonance imaging.

A
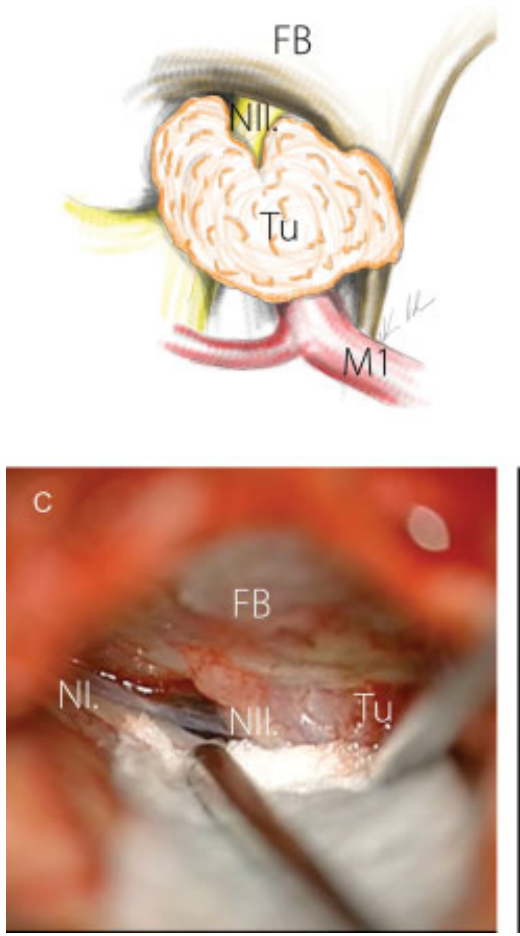

B
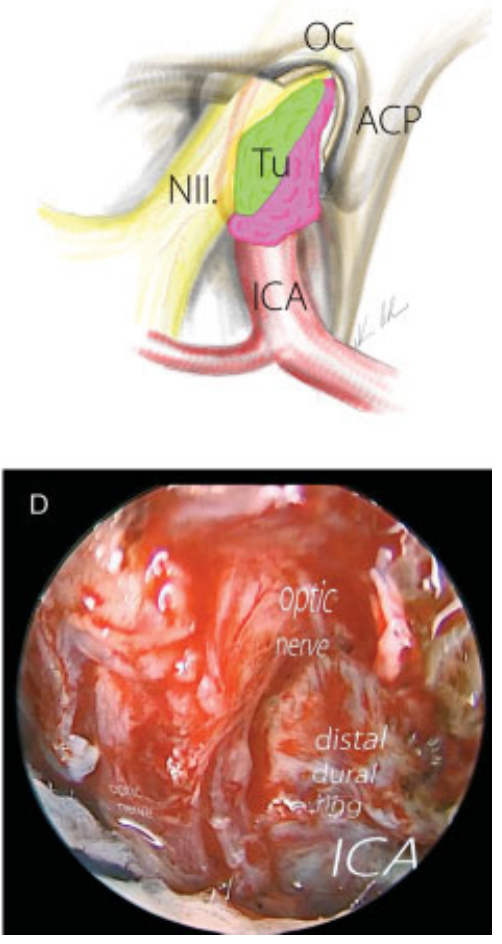

Fig. 2 (A) Schematic representation of the supraoptic tumor parts and their relations to the surrounding neurovascular structures. (B) Schematic drawing of the intracanalicular tumor parts within the right optic canal after partial decompression. The surrounding neurovascular structures, such as the optic nerve, ophthalmic artery, and the anterior clionid process, are visible in relation to the tumor. (C) Intraoperative image through the operating microscope. Through the subfrontal approach, the supraoptic tumor parts are visible. (D) Endoscopic image through a 30-degree optic directed to the frontal base after decompression of the right optic nerve and complete tumor removal. ACP, anterior clinoid process; FB, frontal base; ICA, internal carotid artery; M1, middle cerebral artery; NI, olfactory nerve; NII, optic nerve; OC, optic canal; Tu, tumour. 